\title{
Article \\ Surgical Outcome in Extratemporal Epilepsies Based on Multimodal Pre-Surgical Evaluation and Sequential Intraoperative Electrocorticography
}

\author{
Lilia María Morales Chacón *, Judith González González, Martha Ríos Castillo, Sheila Berrillo Batista, \\ Karla Batista García-Ramo, Aisel Santos Santos, Nelson Quintanal Cordero, Marilyn Zaldívar Bermúdez, \\ Randis Garbey Fernández, Bárbara Estupiñan Díaz, Zenaida Hernández Díaz, Juan E. Bender del Busto, \\ Abel Sánchez Coroneux, Margarita M. Báez Martin and Lourdes Lorigados Pedre
}

check for updates

Citation: Chacón, L.M.M.; González González, J.; Ríos Castillo, M.; Berrillo Batista, S.; García-Ramo, K.B.; Santos Santos, A.; Cordero, N.Q.; Bermúdez, M.Z.; Garbey Fernández, R.; Estupiñan Díaz, B.; et al. Surgical Outcome in Extratemporal Epilepsies Based on Multimodal Pre-Surgical Evaluation and Sequential Intraoperative Electrocorticography. Behav. Sci. 2021, 11, 30.

https://doi.org/10.3390/bs11030030

Academic Editor: Dario Siniscalco

Received: 25 December 2020

Accepted: 19 February 2021

Published: 4 March 2021

Publisher's Note: MDPI stays neutra with regard to jurisdictional claims in published maps and institutional affiliations.

Copyright: (c) 2021 by the authors. Licensee MDPI, Basel, Switzerland. This article is an open access article distributed under the terms and conditions of the Creative Commons Attribution (CC BY) license (https:// creativecommons.org/licenses/by/ $4.0 /)$.
International Center for Neurological Restoration, National Epilepsy Surgery Program, 25th Ave, No 15805, Havana PC 11300, Cuba; judith@neuro.ciren.cu (J.G.G.); martharios@neuro.ciren.cu (M.R.C.); sheylabb@infomed.sld.cu (S.B.B.); kbatista.gr@gmail.com (K.B.G.-R.); aisel.santos@gmail.com (A.S.S.); nquintanal@neuro.ciren.cu (N.Q.C.); marilyn@neuro.ciren.cu (M.Z.B.); randis0770@gmail.com (R.G.F.); baby@neuro.ciren.cu (B.E.D.); zmhernandez@neuro.ciren.cu (Z.H.D.); jebender@infomed.sld.cu (J.E.B.d.B.); abel@neuro.ciren.cu (A.S.C.); minou@neuro.ciren.cu (M.M.B.M.); lourdes.lorigados@infomed.sld.cu (L.L.P.)

* Correspondence: lilia.morales@infomed.sld.cu; Tel.: +537-273-0920

Abstract: Objective: to present the postsurgical outcome of extratemporal epilepsy (ExTLE) patients submitted to preoperative multimodal evaluation and intraoperative sequential electrocorticography (ECoG). Subjects and methods: thirty-four pharmaco-resistant patients with lesional and non-lesional ExTLE underwent comprehensive pre-surgical evaluation including multimodal neuroimaging such as ictal and interictal perfusion single photon emission computed tomography (SPECT) scans, subtraction of ictal and interictal SPECT co-registered with magnetic resonance imaging (SISCOM) and electroencephalography (EEG) source imaging (ESI) of ictal epileptic activity. Surgical procedures were tailored by sequential intraoperative ECoG, and absolute spike frequency (ASF) was calculated in the pre- and post-resection ECoG. Postoperative clinical outcome assessment for each patient was carried out one year after surgery using Engel scores. Results: frontal and occipital resection were the most common surgical techniques applied. In addition, surgical resection encroaching upon eloquent cortex was accomplished in $41 \%$ of the ExTLE patients. Pre-surgical magnetic resonance imaging (MRI) did not indicate a distinct lesion in $47 \%$ of the cases. In the latter number of subjects, SISCOM and ESI of ictal epileptic activity made it possible to estimate the epileptogenic zone. After oneyear follow up, $55.8 \%$ of the patients was categorized as Engel class I-II. In this study, there was no difference in the clinical outcome between lesional and non lesional ExTLE patients. About $43.7 \%$ of patients without lesion were also seizure- free, $p=0.15$ (Fischer exact test). Patients with satisfactory seizure outcome showed lower absolute spike frequency in the pre-resection intraoperative ECoG than those with unsatisfactory seizure outcome, (Mann- Whitney $\mathrm{U}$ test, $p=0.005)$. Conclusions: this study has shown that multimodal pre-surgical evaluation based, particularly, on data from SISCOM and ESI alongside sequential intraoperative ECoG, allow seizure control to be achieved in patients with pharmacoresistant ExTLE epilepsy.

Keywords: extratemporal epilepsy surgery; multimodal neuroimaging; intraoperative electrocorticography; seizure outcome

\section{Introduction}

Extratemporal epilepsy (ExTLE) embraces a variety of seizures which can arise from the cerebral cortex outside of the temporal lobe [1]. Thus, epilepsy surgery constitutes an effective treatment for carefully selected patients with pharmacoresistant epilepsies, even when the outcomes of surgical treatment in ExTLE are less satisfactory compared to 
temporal lobe epilepsy (TLE) [2,3]. On the other hand, patients with magnetic resonancenegative focal epilepsy show less favorable surgical outcomes compared to those in whom an magnetic resonance imaging (MRI) lesion guides the site of surgical intervention [3,4].

Surgical treatment of ExTLE is still challenging due to hitches in defining the epileptogenic zone (EZ). Nonetheless, current advances in noninvasive techniques such as epilepsy specific MRI and functional neuroimaging - single photon emission-computed tomography (SPECT) and positron emission tomography (PET) - have improved the diagnostic tools of ExTLE, facilitating surgical treatment [4-6]. Equally, intraoperative electrocorticography (ECoG) may provide significant information concerning electrographic activity, which modifies the resection extension [7].

Apart from the ambiguity regarding the choice of the most prospective candidates, surgical treatment of ExTLE still has difficulties in localizing and defining the extension of the EZ. This paper summarizes post-surgical assessment in both lesional and non lesional extratemporal epilepsies patients, submitted to a preoperative multimodal evaluation including neuroimaging; explicitly, subtraction of ictal and interictal SPECT co-registered with magnetic resonance imaging (SISCOM) and electroencephalography (EEG) source imaging (ESI) of ictal epileptic activity as well as sequential intraoperative ECoG during surgical resective and/or disconnective procedures.

\section{Subjects and Methods}

Patients with pharmacoresistant epilepsy were referred from all regions of the country covering urban and rural areas. Eligibility criteria required individuals to be non-responsive to at least two appropriate antiepileptic drugs (AEDs) trials due to inefficacy or intolerance; hence, recurrently compromised by seizures [8].

Family and patient's consent was received in all cases. Subjects submitted to ExTLE epilepsy surgery with one-year follow-up after surgical procedure were included in this communication whereas those with prior brain operation were left out. In addition, clinical outcome data were collected prospectively at the International Center for Neurological Restoration, Havana Cuba from 2016 until 2019.

Preoperative evaluation included: (a) prolonged video-electroencephalography (VEEG) monitoring with scalp electrodes and additional electrodes considering the epileptogenic zone presumed; (b) MRI scans with a $1.5 \mathrm{~T}$ or 3T scanner (Siemens Magnetom Symphony); (c) a comprehensive battery of neuropsychological tests (executive functions, attention and memory assessment, higher verbal and visual functions) and; (d) multimodal evoked potentials, somatosensory, visual and auditive [9-11]. Interictal and ictal brain single photon emission computed tomography with EEG co-registration was also carried out in patients with non-visible lesion in MRI. Additionally, ictal ESI, SISCOM and MRI post processing were performed in this patient group in accordance with our previously published protocol [10].

\subsection{Video Electroencephalography (EEG)-Based Diagnostics}

Patients underwent video-EEG monitoring for $8.7 \pm 2.7$-day. The distribution of interictal epileptiform discharges (IEDs) during prolonged video-EEG monitoring was assessed by (LM) through the analysis of 15-min-interictal EEG samples every one hour. The data recorded in relation to seizures were identified by button presses or by seizure or spike detection programs.

Furthermore, interictal epileptiform activity and ictal onset pattern were categorized as: (1) regional involving one lobe, and ipsilateral contiguous or, (2) non-regional. Ictal and interictal video-EEG were examined by a highly qualified epileptologist involved in this study (LM). One year following surgery, extracraneal prolonged EEG was also recorded (data not reported). 


\subsection{Pre-Surgical Neuroimaging-Based Diagnostics}

Pre-surgical $1.5(n=13)$ or 3T $(n=21)$ MRI scans of the patients integrating T1weighted images with and without gadolinium-DTPA, T2-weighted images, fluid-attenuated inversion recovery images, and magnetization-prepared rapid gradient echo sequences were reviewed by a versed neuroradiologist $(\mathrm{ZH})$.

MRI findings were classified as (1) MR visible/MR non-visible; (2) tumor, cortical development malformation, vascular lesions, among others; (3) eloquent cortex/non-eloquent adjacent to or overlapping with eloquent areas-the primary motor cortex or Broca's area, sensorial, language-based on anatomic landmarks; and (4) laterality-dominant hemisphere/non-dominant. Moreover, eloquent cortical areas were designated according to Chang et al.'s classification, which comprised the rolandic cortex (pre- and postcentral gyrus), the supplementary motor area (SMA), insula, and primary visual cortex as well as Broca and Wernicke's areas [12].

\subsection{Single Photon Emission-Computed Tomography (SPECT) Co-Registered with Magnetic Resonance Imaging (MRI) (SISCOM)}

Brain perfusion SPECT was carried out in patients with non lesional extratemporal epilepsies. SPECT image acquisition was performed using a double-headed gamma camera (SMV DST-XLi, Buc Cedex, France) equipped with a fan-beam collimator. For co-registration with the MRI scan, the cerebral surface of the MRI volume was segmented from the extracerebral structures. Subsequently, the cerebral surface of the binary ictal SPECT was matched to the cerebral surface of the binary MRI. The resulting transformation matrix was then applied to the subtraction SPECT to co-register it to the cerebral surface of the MRI. Furthermore, each patient underwent two studies (Ictal and Inter-ictal) of brain perfusion SPECT using 99mTc-ethylene-cysteine dimer (ECD). In both studies, the subject remained monitored by EEG during the administration of the $99 \mathrm{~m}$ Tc ECD. For ictal SPECT, the radiotracer was injected when the EEG seizures onset was identified. For inter-ictal SPECT, the dose of the radiotracer was administered with at least a $24 \mathrm{~h}$-seizure-free period.

\subsection{Ictal Electroencephalography Source Imaging (ESI)}

The cortical generators of EEG measurements can be estimated by solving an inverse imaging problem where the unknown sources are distributed on the individual's cortex. The methodology followed in this study for the estimation of the inverse solution of ictal EEG has previously been published [10].

\subsection{Surgical Procedures and Histopathology}

The extension of resection in lesional and non lesional patients was adjusted bearing in mind pre-surgical evaluation, and tailored by sequential pre- and post-resection ECoG. Data acquisition was performed with a Medicid-5 digital Electroencephalographic system (Neuronic SA, Cuba) with 32 channels, $256 \mathrm{~Hz}$ sampling rate and a 16 bit analogue-todigital converter. Data were band-pass filtered between 0.53 and $70 \mathrm{~Hz}$. ECoG analyses were performed by two board-certified electroencephalographers. Additionally, Ad-Tech subdural electrodes (grid and strips) were used. Then, quantification of discharges in each register-electrode was determined by using the Neuronic automatic spike detection system. Two clinical neurophysiology specialists visually reviewed these results for artifacts (LM, SB). All spike activity regarded as artifactual was excluded. Lastly, the absolute spike frequency (ASF, spike/min) was calculated in the pre- and post-resection ECoG.

Accurate identification of lesion localization relative to eloquent cortex was derived from intraoperative ECoG using cortical mapping with evoked potentials and electrical stimulation. Moreover, subtotal resection was intentionally performed when the lesion overlapped with eloquent cortex.

Histopathological findings comprised four chief groups: cortical development malformations, neoplasms, vascular lesions, and other non-specific histopathological abnormalities. In cases of mycroscopic diagnosis, and focal cortical dysplasia (FCD) classification, 
the system proposed by the International League Against epilepsy was used [13]. For histopathological diagnosis of central nervous system tumors, the World Health Organization classification was employed [14]. Neoplasms were categorized as glial tumors (astrocytomas, oligoastrocytomas, and oligodendrogliomas) and neuroepithelial tumors (gangliogliomas and dysembryoplastic neuroepithelial tumors, DNT). On the other hand, non-specific histopathological abnormalities included gliosis, scars, among others were also tabulated.

\subsection{Seizure Outcomes}

Seizure outcome assessment was based on the system proposed by Engel [Engel class I, free of disabling seizures; class IA, seizure-free; class II, rare seizures (less than three seizures per year); class III, worthwhile improvement (reduction in seizures of $80 \%$ or more); class IV, no benefit] [15]. In general, patients classified as Engel class I or II were categorized as satisfactory seizure outcome while those included in Engel class III or IV were labelled as unsatisfactory. Subjects were routinely evaluated 12 months following surgery.

\subsection{Statistics Analysis}

Indicators were summarized with descriptive statistics for each variable comprising mean, median, and standard deviations for continuous variables, and frequencies for categorical ones. STATISTICA (data analysis software system), version 8.0, www.statsoft. com.Tulsa, USA). Finally, Mann Whitney and Wilcoxon tests were applied for independent and dependent samples respectively. Exact $p$ values generated for small and moderate samples were taken for significance evaluation, then statistical significance was set at $p<0.05$.

\subsection{Ethical Considerations}

The procedures performed followed the 1975 Declaration of Helsinki for human research. Correspondingly, this study was approved by the scientific and ethics committee of the International Center for Neurological Restoration (CIREN37/2012).

\section{Results}

\subsection{Preoperative Evaluation}

Thirty-four patients (28 males) were included in this study (Table 1). Mean age at surgery was 24.38 years (standard deviation 8.8 , range 8-47) with average epilepsy duration of 16.79 years (standard deviation 9.5 ranged $3-42$ ). Mean age at seizure onset was $7.6 \pm 5.7$ (ranged 5 months to 21 years) Table 1 , and pre-surgical seizure frequency was $20 /$ months or more in $76.4 \%$ (26). Also, risk factors were considered in 27 of the patients. 
Table 1. Demographic, clinical and surgery profile.

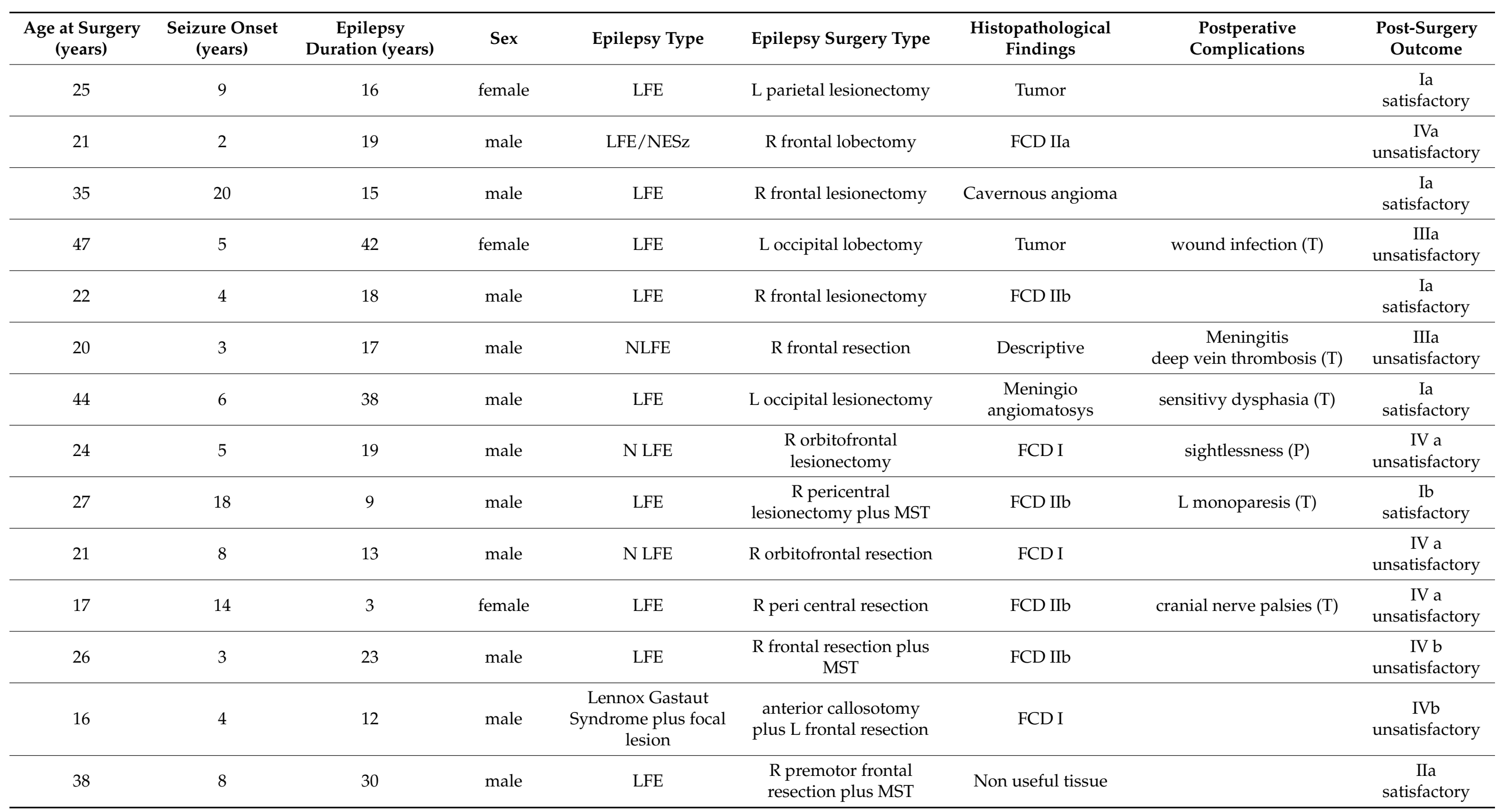


Table 1. Cont

\begin{tabular}{|c|c|c|c|c|c|c|c|c|}
\hline $\begin{array}{l}\text { Age at Surgery } \\
\text { (years) }\end{array}$ & $\begin{array}{l}\text { Seizure Onset } \\
\text { (years) }\end{array}$ & $\begin{array}{c}\text { Epilepsy } \\
\text { Duration (years) }\end{array}$ & Sex & Epilepsy Type & Epilepsy Surgery Type & $\begin{array}{l}\text { Histopathological } \\
\text { Findings }\end{array}$ & $\begin{array}{l}\text { Postperative } \\
\text { Complications }\end{array}$ & $\begin{array}{l}\text { Post-Surgery } \\
\text { Outcome }\end{array}$ \\
\hline 22 & 9 & 13 & female & LFE/NESz & $\begin{array}{l}\mathrm{R} \text { parietotemporal } \\
\text { lesionectomy }\end{array}$ & Tumor & & $\begin{array}{c}\text { Ia } \\
\text { satisfactory }\end{array}$ \\
\hline 29 & 14 & 15 & male & LFE & $\begin{array}{l}\mathrm{R} \text { frontal lesionectomy } \\
\text { plus disconnection }\end{array}$ & FCD IIb & $\begin{array}{c}\text { cerebrospinal fluid leak } \\
(\mathrm{T})\end{array}$ & $\begin{array}{c}\text { Ic } \\
\text { satisfactory }\end{array}$ \\
\hline 22 & 5 & 17 & male & NLFE & $\begin{array}{l}\text { R midlle frontal gyrus } \\
\text { topectomy plus MST }\end{array}$ & FCD I & & $\begin{array}{c}\text { IV a } \\
\text { unsatisfactory }\end{array}$ \\
\hline 24 & 0 & 24 & male & NLFE & $\mathrm{R}$ frontal lobectomy & Descriptive & & $\begin{array}{c}\mathrm{Ib} \\
\text { satisfactory }\end{array}$ \\
\hline 24 & 15 & 9 & male & NLFE & $\begin{array}{l}\mathrm{R} \text { frontal Resection plus } \\
\text { anterior callosotomy }\end{array}$ & FCD IIa & & $\begin{array}{c}\text { IIIa } \\
\text { unsatisfactory }\end{array}$ \\
\hline 23 & 22 & 1 & female & NLFE & $\begin{array}{l}\mathrm{L} \text { frontal resection plus } \\
\text { anterior callosotomy }\end{array}$ & FCD IIa & & $\begin{array}{c}\text { IIb } \\
\text { satisfactory }\end{array}$ \\
\hline 29 & 26 & 3 & male & LFE & L frontal lesionectomy & FCD IIa & & $\begin{array}{c}\text { Ic } \\
\text { satisfactory }\end{array}$ \\
\hline 32 & 11 & 21 & male & LFE & L frontal topectomy & FCD Ia & Hemiparesis $(\mathrm{P})$ & $\begin{array}{c}\mathrm{IVc} \\
\text { unsatisfactory }\end{array}$ \\
\hline 37 & 31 & 6 & male & N LFE & $\begin{array}{l}\text { R superior frontal gyrus } \\
\text { resection and midlle } \\
\text { gyrus topectomy plus } \\
\text { callosotomy }\end{array}$ & FCD Ia & $\begin{array}{l}\text { disconnection syndrome } \\
(\mathrm{T})\end{array}$ & $\begin{array}{c}\text { Ia } \\
\text { satisfactory }\end{array}$ \\
\hline 19 & 19 & 0 & male & $\begin{array}{l}\text { Lennox Gastaut } \\
\text { Syndrome }\end{array}$ & anterior callosotomy & No tissue & $\begin{array}{l}\text { disconnection syndrome } \\
(\mathrm{T})\end{array}$ & $\begin{array}{c}\text { IIIa } \\
\text { unsatisfactory }\end{array}$ \\
\hline 21 & 3 & 18 & male & LFE & $\begin{array}{l}\text { L superior frontal gyrus } \\
\text { corticectomy and midlle } \\
\text { gyrus topectomy }\end{array}$ & FCD Ic & & $\begin{array}{c}\text { Ia } \\
\text { satisfactory }\end{array}$ \\
\hline
\end{tabular}


Table 1. Cont.

\begin{tabular}{|c|c|c|c|c|c|c|c|c|}
\hline $\begin{array}{l}\text { Age at Surgery } \\
\text { (years) }\end{array}$ & $\begin{array}{l}\text { Seizure Onset } \\
\text { (years) }\end{array}$ & $\begin{array}{c}\text { Epilepsy } \\
\text { Duration (years) }\end{array}$ & Sex & Epilepsy Type & Epilepsy Surgery Type & $\begin{array}{l}\text { Histopathological } \\
\text { Findings }\end{array}$ & $\begin{array}{l}\text { Postperative } \\
\text { Complications }\end{array}$ & $\begin{array}{l}\text { Post-Surgery } \\
\text { Outcome }\end{array}$ \\
\hline 18 & 10 & 8 & male & NLFE & $\begin{array}{l}\text { L parietal topectomy } \\
\text { and posterior } \\
\text { disconnection }\end{array}$ & FCD Ia & & $\begin{array}{l}\mathrm{Ib} \\
\text { satisfactory }\end{array}$ \\
\hline 18 & 15 & 3 & male & NLFE & $\begin{array}{l}\text { L frontal gyrus } \\
\text { corticectomy plus } \\
\text { callosotomy }\end{array}$ & descriptive & $\begin{array}{l}\text { disconnection syndrome } \\
\text { (T) }\end{array}$ & $\begin{array}{c}\text { IIIa } \\
\text { unsatisfactory }\end{array}$ \\
\hline 11 & 10 & 1 & male & $\begin{array}{l}\text { Lennox Gastaut } \\
\text { Syndrome plus focal } \\
\text { lesion }\end{array}$ & $\begin{array}{c}\text { R occipital } \\
\text { disconnection }\end{array}$ & polymicrogyria & & $\begin{array}{c}\text { IIIa } \\
\text { unsatisfactory }\end{array}$ \\
\hline 17 & 14 & 3 & female & NLFE & $\begin{array}{l}\text { L frontal resection plus } \\
\text { MST }\end{array}$ & FCD Ia & & $\begin{array}{c}\text { IIa } \\
\text { satisfactory }\end{array}$ \\
\hline 15 & 4 & 11 & male & $\begin{array}{l}\text { Lennox Gastaut } \\
\text { Syndrome plus focal } \\
\text { dysfunction }\end{array}$ & $\begin{array}{l}\text { L frontal resection plus } \\
\text { anterior callosotomy } \\
\text { plus disconnection }\end{array}$ & descriptive & hemiparesis $(\mathrm{T})$ & $\begin{array}{c}\text { IIIa } \\
\text { unsatisfactory }\end{array}$ \\
\hline 8 & 5 & 3 & male & NLFE & $\begin{array}{l}\mathrm{R} \text { frontal resection plus } \\
\text { MST }\end{array}$ & FCD I & & $\begin{array}{c}\mathrm{Ib} \\
\text { satisfactory }\end{array}$ \\
\hline
\end{tabular}

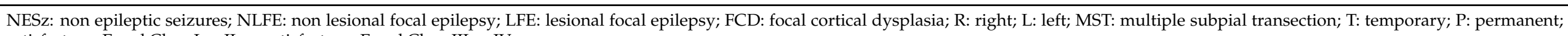
satisfactory: Engel Class I or II; unsatisfactory: Engel Class III or IV. 
All participants who matched the selection criteria were taking 2-4 antiepileptic drugs (AEDs). Lamotrigine, carbamazepine, clonazepan, valproic acid, clobazan and levetiracetan were the most frequent prescriptions, and the mean number of antiepileptic drugs at surgery time was $2,87 \pm 0.83$.

\section{Multimodal Pre-Operative Assessment}

During extracranial video-EEG monitoring, a mean of $20.6 \pm 15.9$ seizures per patient was recorded with a mean video-EEG monitoring efficiency equal 0.77 . Data with reference to awake and sleep seizures day-to-day were 1.55 and 0.9 , respectively.

Furthermore, regional interictal EEG pattern was recorded in $53.8 \%$ (18) of the patients while $74 \%$ (25) exhibited non-lateralized or bilateral interictal epileptiform discharges (IED). In contrast, ictal EEG pattern was lateralized in $71.4 \%$ (24) and regional in $82.3 \%$ (28) of the subjects. Non-aware focal seizures were the most frequent seizure type, $38.2 \%$ $(13 / 34)$, which then evolved to bilateral tonic clonic seizures. On the other hand, aware focal seizures changed to non-aware and bilateral tonic clonic seizures, which was noticed in $26.4 \%$ (9/34). Non-epileptic seizures were also reported in two of the patients along with epileptic seizures.

Although the attention in this work is not focused on the evaluation of the neuropsychological functioning in these patients, it is important to note that no significant differences were found in the executive function scales between pre- and post-operative evaluations. $p=0.32$ Wilcoxon matched pairs test. Furthermore, impairment in the domain of phonological fluency was evidenced in the pre-operative evaluation in $84 \%$ of the patients, and $80 \% . p=0.32$ in the post-surgery stage.

Magnetic resonance imaging did not indicate a distinct lesion in 16 patients (47\%), 13 of whom were submitted to a methodology combining non-invasive functional modalities, subtraction of ictal and interictal SPECT co-registered with magnetic resonance imaging (SISCOM) and EEG source imaging (ESI) of ictal epileptic activity to estimate the location of the EZ. The findings of both methodologies showed high relation to the resection zone in Engel I-II subjects Figure 1.

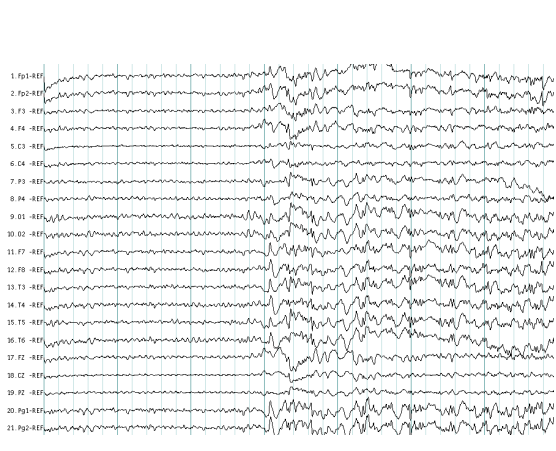

(A)

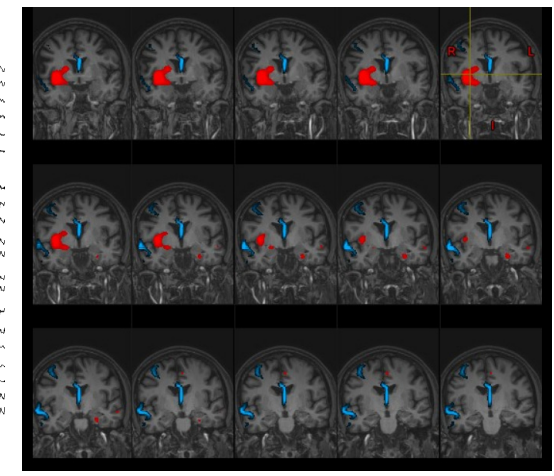

(B)

Figure 1. Multimodal evaluation in non-lesional extratemporal epilepsy patient. (A) Ictal scalp electroencephalography (EEG) pattern at seizure onset during habitual non aware focal motor seizures which evolved to bilateral tonic clonic seizures. Visual EEG localization did not show a clear lateralized and localized seizure onset zone. (B) In red, computer- aided subtraction ictal single photon emission-computed tomography (SPECT) co-registered to MRI (SISCOM) of the patient indicated localized areas of hyperperfusion (insula, inferior opercular frontal, putamen, amygdala, and anterior cingulum of the right hemisphere). In blue, estimation of ictal EEG source imaging (ESI) discharges at seizure onset also demonstrated a localize ictal source in this patient (right middle frontal gyrus, right superior temporal and middle line). 


\subsection{Epilepsy Surgery Procedures and Surgical Outcome}

3.2.1. Surgical Techniques were Classified as Resective, Disconnective and Combined

Adjusted frontal lobectomy $21(61.7 \%)$, as well as occipital and parietal were the most common resection procedures. About $65.5 \%(19 / 29)$ of the resective surgeries was done in non-dominant hemispheres whereas 14 (41.17\%) of the ExTLE patients undertook surgical resection encroaching upon the eloquent cortex. Multiple subpial transection was undertaken additionally to resection in eloquent areas in six of the subjects (three in frontal, and three in pericentral cortex). Both focal resection and anterior callosotomy were carried out in six of the cases. The four disconnective procedures performed included two frontal and two occipital Table 1.

\subsubsection{Surgical Outcome and Intraoperative ECoG}

After one-year follow up, 19/34 (55.8\%) of the patients had a satisfactory seizure outcome (Engel class I-II). In this arm, the highest frequency was occupied by cases classified within class I, 16/19 (84, 2\%). Engel scores follow-up for this group were as follows: 9 class IA, 5 IB, 2 IC and 3 II. On the other hand, Engel scores follow-up for unsatisfactory seizure outcome (Engel class III-IV) patients was described as 7 class III and 8 class IV. In the current study, there was no difference in the clinical outcome between lesional and non lesional ExTLE patients, $p=0.15$, Fischer exact test Figure 2. Of the 19 patients who were seizure-free, seven had no macroscopic lesion in MRI.
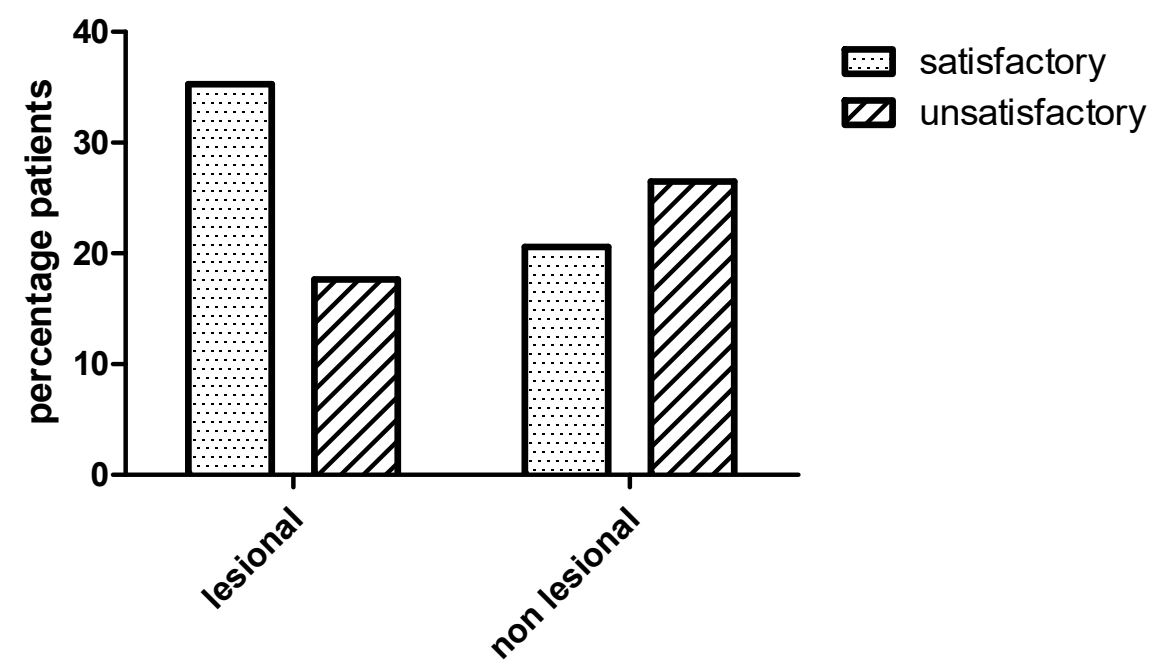

Figure 2. Bar graph showing clinical outcome between lesional and non lesional extraemporal epilepsies patients. There was no difference in the clinical outcome between lesional and non lesional patients (Fischer exact test, $p=0.15$ ). Satisfactory (Engel class I-II) and unsatisfactory (Engel class III-IV) outcome one year after surgery.

One of the two patients reported who had non-epileptic seizures in addition to epileptic ones was seizure-free for both epileptic and non-epileptic seizures whereas the other was classified as Engel IVA class, screening a decrease in the frequency of non-epileptic seizures evaluated by video-EEG.

All patients were submitted to pre-resection and sequential post-resection ECoG. Repetitive interictal spikes and other specific patterns were seen in 79.4\% (27). The absolute spike frequency diminished significantly in the last post-resection ECoG (Wilcoxon matched pairs test, $p=0.002$ ) Figure 3. Furthermore, patients with satisfactory seizure outcome showed lower absolute spike frequency in the pre-resection ECoG $(11.3 \pm 3.6 / \mathrm{min})$ than those with seizure recurrence $(38.3 \pm 10.6 / \mathrm{min})$, Mann-Whitney $\mathrm{U}$ test, $p=0.005$ Figure 4 . 


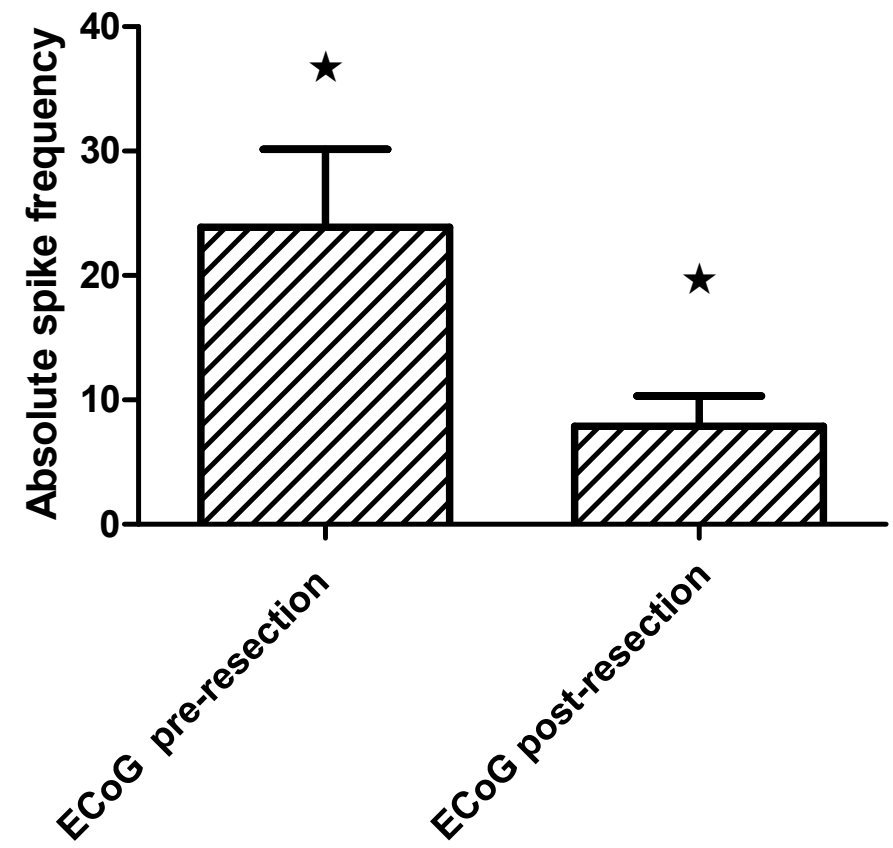

Figure 3. Bar grah showing absolute spike frequency on the pre and post-resection intraoperative electrocorticography (mean and standard error SE) in extratemporal epilepsies patients (Wilcoxon matched pairs test, $\left.{ }^{*} p=0.002\right)$.

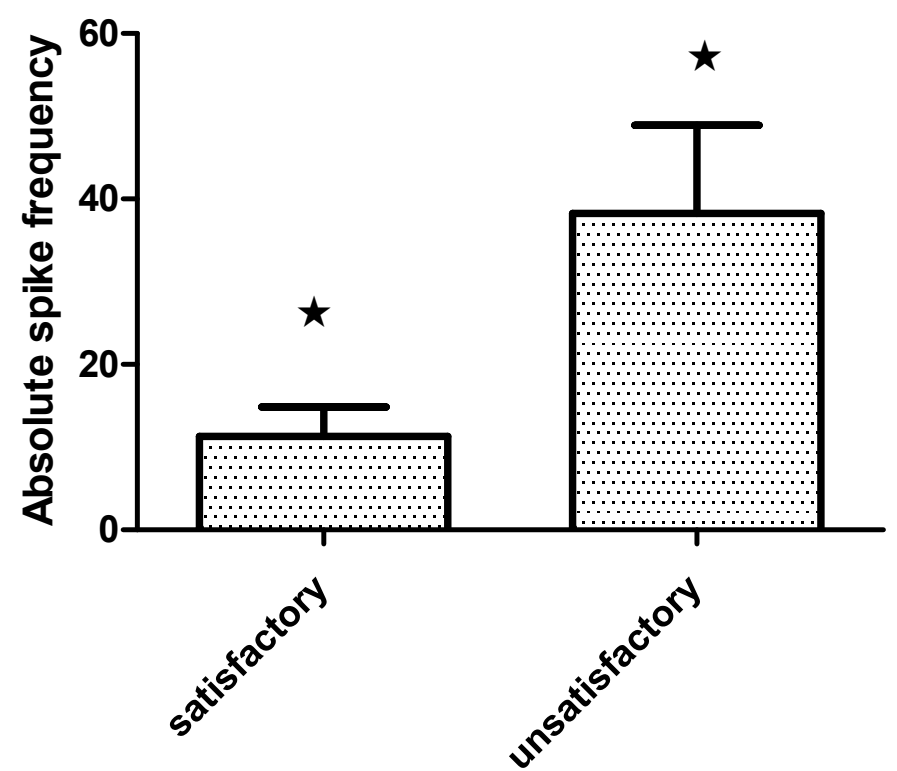

Figure 4. Bar grah showing absolute spike frequency on the pre-resection intraoperative Electrocorticography.(ECoG) (mean and standard error SE) in extratemporal epilepsies patients with satisladory·(Engel class I-II) and unsatisactory (Engel class III-IV) outcome one year after surgery (Mann Whitney U test, ${ }^{*} p=0.005$ ).

\subsubsection{Histopathological Findings}

As can be seen from Table 1, malformations of cortical development accounted for $21 / 28(75 \%)$ of all histopathological findings accompanied by neoplasms. There was a similar proportion of patients with FCD type I 10/21 (47.6\%), and Type II 11/21(52.3\%), $p=0.74$. In addition, neoplasms astrocytoma and ganglioglioma were observed in three patients. 


\subsubsection{Operative Complications}

Permanent neurological morbidity was detected in three of the patients $(8.8 \%)$, described as paresis, dysphasia, and sightlessness. As shown in Table 1, there was no mortality in our cohort. On the other hand, one patient classified as Engel Class I died from cardiovascular disease 15 months post-surgery.

\subsection{Discussion}

The most important clinically relevant finding was that $55.8 \%$ of the patients with extratemporal epilepsy had a satisfactory seizure outcome (Engel class I-II), of whom 84, $2 \%$ were in Engel class I. The clinical outcome was similar in lesional and non lesional. ExTLE patients. In the second group, a relatively high incidence of FCD type I was found. The findings of this study suggest that multimodal evaluation combined with sequential intraoperative ECoG can facilitate satisfactory seizures outcome.

There is evidence that patients with a lesion in the MRI show the best seizure outcome after surgical procedures in temporal and extratemporal epilepsies [16-26]. However, it is important to note that, in our series, almost half of the patients who had non-lesional epilepsy were submitted to surgery without invasive EEG. It is interesting to signal that most of our patients exhibited non-aware focal seizures which then evolved to bilateral tonic clonic. During seizures, EEG pattern was predominantly regional and lateralized. However, interictal EEG pattern was regional and non-lateralized.

It is a widely held view that surface electroencephalography is an essential method for the diagnosis, characterization and localization of extratemporal neocortical epilepsies; however, it has low sensibility compared to identical application for temporal epilepsies. In addition, interictal epileptiform discharges (IED) occur in $60 \%$ to $80 \%$ of frontal lobe epilepsy, and are considered to be of less localizing value than in TLE as they can be bilateral, multilobar or even generalized. Evidence of focal seizure onset can also be derived from regional EEG slowing or spikes [11,20,21].

There is strong evidence that for occipital, frontal, and parietal lobe epilepsies, the evaluation and localization of epileptic discharges by surface EEG are very challenging. This determines the difficulties not only to localize but also to define a false lateralization. For occipital lobe epilepsies, the difficulty of lateralization is added to a diffusion of discharges, in many cases, to ipsilateral temporal lobe with clinical manifestations similar to those of temporal lobe [17]. Notably, intracranial EEG is often used to localize the area responsible for seizure, but as this is an invasive technique, it cannot sample the activity from the whole brain.

A multimodal evaluation, specifically the use of SISCOM and ESI, developed by our group enabled satisfactory outcomes without intracranial EEG. Brain perfusion, ictal and interictal SPECT, along with SISCOM offered a high criterion of veracity in ictal onset detection represented by an increase in cerebral blood perfusion [10]. Previous studies have reported a sensitivity of interictal SPECT of $44 \%$, and ictal over $97 \%$ in temporal lobe epilepsy, contrary to a sensitivity of $66 \%$ in ictal and $40 \%$ interictal in extra-temporal epilepsy $[5,6,10]$.

On the other hand, ESI allowed us to infer the configuration of neuronal sources responsible for ictal activity. A further 13/16 (81.25\%) non-lesional epilepsy patients went through multimodal neuroimaging evaluation with SISCOM and ESI. The findings of both methodologies showed a high relation to the resection zone in satisfactory seizure outcome subjects. Recent progress in neurophysiological and neuroimaging techniques has not only significantly improved non-invasive pre-surgical evaluation, but also opened the choice of epilepsy surgery to patients not previously considered surgical candidates $[5,6,10,11]$.

In this study there was no difference in the clinical outcome between non-lesional and lesional ExTLE patients. In the latter group, FCD was the most common histopathological finding, with similar proportion between FCD Type I and Type II. FCD has been identified as a major cause of pharmacoresistant extratemporal resections, especially in children and adolescents [27-29], with a seizure-free rate after resection between $52 \%$ and $68.9 \%$ [30-32]. 
In accordance with previous studies, we found a relatively high incidence of FCD type I among operated patients with normal MRI [33-35]. In this framework, some authors have pointed out that even the invisible underlying pathology, explicitly FCD, may represent a favorable prognostic indicator in case of complete removal of the EZ when compared with all other etiologies [36-38].

In a recent extratemporal series, FCD accounted for $46.5 \%$ of all histopathological findings together with tumors, gliosis, and cavernomas [3]. Similarly, astrocytomes and gangliogliomas were the tumors identified in our patients; being the latter of the group of long-term epilepsy-related tumors. With respect to histopathology, more favorable seizure outcomes have been described in patients with cavernomas and glioneuronal tumors (gangliogliomas and DNTs with $89 \%$ and $85 \%$ seizure-free (Engel I) patients, respectively. Consistent with other research, $2 / 3(66.6 \%)$ of our patients with tumor conditions remained seizure-free.

Even with the aforementioned neuroimaging and histopathological profile, our seizure outcome matches those observed in earlier studies. One year after surgery, 55.8\% of the extratemporal epilepsies patients with lesional and non-lesional epilepsy were categorized as satisfactory seizure outcome (Engel I-II class). Likewise, the surgical outcome in our cohort is in agreement with a large case series of surgery for extratemporal lobe epilepsies reported, in which $49 \%$ of the patients were Engel IA at an average of 54 months postoperatively [3]. In Delev D's report, Engel I outcome after frontal and parietal resections was $65 \%$ and $71 \%$, correspondingly, while other studies informed Engel I outcome ranging from $45.1 \%$ to $57.5 \%$ [16-18]. The results of this study are also in line with a meta-analysis described by Tellez-Zenteno et al., and slightly better compared to other series [19]. Some specialists from developing countries involved in temporal and extratemporal epilepsy surgery have reported Engel class I outcome in about 60\% at 12 months' follow-up [20-22]

Most procedures carried out for extratemporal epilepsies in this study are frontal resections [26], accounting for $61.7 \%$ of our cluster, followed by occipital, parietal and pericentral resection, or combined with disconnection techniques. This finding is in agreement with findings in Delev D's series which described $48 \%$ of frontal lobe operations, and $24 \%$ parietal, occipital, and insular resections [3]. They also reported that the most positive epileptological outcomes were achieved in individuals with frontal and parietal resections (Engel I $65.0 \%$ and $71.4 \%$, respectively), in contrast to insular resections, revealing less auspicious results (Engel I 52.2\%).

Outstandingly, such comparisons are limited by both referral patterns and selection criteria, which are likely to fluctuate from different centers in Latin American countries. In order to homogenize these criteria, our cases were discussed in an epilepsy surgery conference including a multidisciplinary team of the epilepsy surgery program.

It has commonly been assumed that the success of epilepsy surgery depends upon accurate localization and complete resection of the epileptogenic tissue, which are both aided by intraoperative ECoG. Moreover, the presence of persistent spikes on post-resection ECoG has been a significant statistical association with poor seizure freedom post-surgery [39]. It is also recognized that intraoperative ECoG is a valuable adjunctive test in epilepsy surgery to accomplish ideal seizure freedom in cases of mesial temporal sclerosis plus focal cortical dysplasia and tumors. In the current study, a significant difference was observed between pre- and post-resection absolute spike frequency (ASF) during sequential intraoperative ECoG.

In terms of complications, the rate is higher in extratemporal location compared to temporal resections with a reported perioperative mortality of $1.2 \%$ in extratemporal resections [40]. Appreciably, permanent morbidity of extratemporal procedures varies in different series between 3\% and $43 \%$. The most frequent harms include visual field defects, hemiparesis, aphasia, as well as cranial nerve palsies. There are other reports in which the neurological complications of resective surgery led to a temporary morbidity of $10.9 \%$ and a permanent morbidity of $4.7 \%$ [41-43]. Consistent with those of Delev D's series, in this study, there was no mortality, and permanent morbidities were observed 
in three of the cases (8.8\%), regardless surgical procedures [3]. This number corroborates those of the previous studies that have reported a permanent morbidity between $10 \%$ and $15 \%[3,23,24,44]$.

A limitation of this study is the relatively small number of patients that precluded the extraction of valuable information about potential prognostic factors in seizure recurrence. On the other hand, further research should be undertaken to evaluate the predictive value of the multimodal evaluation in ExTLE epilepsy surgeries. Nonetheless, the results of the current study support the possibility of conducting epilepsy surgery as an effective treatment for carefully selected patients with pharmaco-resistant extratemporal epilepsy. This study indicates that multimodal pre-surgical evaluation based on data resulting from video-EEG neuroimaging, specifically SISCOM and ESI in addition to sequential intraoperative ECoG, allow seizure control to be achieved in patients with pharmacoresistant extratemporal epilepsy.

Author Contributions: L.M.M.C. was in charge of designing the project, analyzing the results, as well as writing the paper. J.G.G., S.B.B., A.S.S., J.E.B.d.B. identified and evaluated the patients with epilepsy. K.B.G.-R.; M.Z.B.; Z.H.D., A.S.C.; M.M.B.M.; L.L.P. participated in the pre and postsurgical evaluation. M.R.C.; N.Q.C., R.G.F. participated in the surgical operation and postsurgical evaluation. B.E.D. participated in the histhopathological analysis. All authors have read and agreed to the published version of the manuscript.

Funding: This research received no external funding.

Institutional Review Board Statement: The study was conducted according to the guidelines of the Declaration of Helsinki, The studies involving human participants were reviewed and approved by scientific and ethics committee of the International Center for Neurological Restoration (CIREN37/2012).

Informed Consent Statement: Written consent was received from all participants. Equally, all parents provided permission for their children to take part in the study.

Acknowledgments: The authors would like to sincerely thank all the members of the epilepsy surgery program from the International Center for Neurological Restoration in Havana, Cuba; especially, the nurses from the telemetry unit and the operation room for their collaboration and support. We are also grateful to our reviewers for their helpful comments.

Conflicts of Interest: The authors declare no conflict of interest.

\section{References}

1. Mihara, T. Surgical treatment for extratemporal lobe epilepsy. Rinsho Shinkeigaku 2005, 45, 924-927. [PubMed]

2. Roper, S.N. Surgical treatment of the extratemporal epilepsies. Epilepsia 2009, 50, 69-74. [CrossRef] [PubMed]

3. Delev, D.; Oehl, B.; Steinhoff, B.J.; Nakagawa, J.; Scheiwe, C.; Schulze-Bonhage, A.; Zentner, J. Surgical Treatment of Extratemporal Epilepsy: Results and Prognostic Factors. Neurosurgery 2018, 84, 242-252. [CrossRef]

4. Ansari, S.F.; Maher, C.O.; Tubbs, R.S.; Terry, C.L.; Cohen-Gadol, A.A. Surgery for extratemporal nonlesional epilepsy in children: A meta-analysis. Childs Nerv. Syst. 2009, 26, 945-951. [CrossRef] [PubMed]

5. Lascano, A.M.; Perneger, T.; Vulliemoz, S.; Spinelli, L.J.-F.; Garibotto, V.; Korff, C.M.; Vargas, M.I.; Michel, C.M.; Seeck, M. Yield of MRI, high-density electric source imaging (HD-ESI), SPECT and PET in epilepsy surgery candidates. Clin. Neurophysiol. 2016, 127, 150-155. [CrossRef]

6. Elkins, K.C.; Moncayo, V.M.; Kim, H.; Olson, L.D. Utility of gray-matter segmentation of ictal-Interictal perfusion SPECT and interictal 18 F-FDG-PET in medically refractory epilepsy. Epilepsy Res. 2017, 130, 93-100. [CrossRef]

7. Greiner, H.M.; Horn, P.S.; Tenney, J.R.; Arya, R.; Jain, S.V.; Holland, K.D.; Leach, J.L.; Miles, L.; Rose, D.F.; Fujiwara, H.; et al. Should spikes on post-resection ECoG guide pediatric epilepsy surgery? Epilepsy Res. 2016, 122, 73-78. [CrossRef]

8. Kwan, P.; Arzimanoglou, A.; Berg, A.T.; Brodie, M.J.; Hauser, W.A.; Mathern, G.; Moshé, S.L.; Perucca, E.; Wiebe, S.; French, J. Definition of drug resistant epilepsy: Consensus proposal by the ad hoc Task Force of the ILAE Commission on Therapeutic Strategies. Epilepsia 2009, 51, 1069-1077. [CrossRef] [PubMed]

9. Báez-Martín, M.M.; Morales-Chacón, L.M.; García-Maeso, I.; Estupiñán-Díaz, B.; Lorigados-Pedre, L.; García, M.E.; Galvizu, R.; Bender, J.E.; Cabrera-Abreu, I.; Pérez-Téllez, Y.; et al. Temporal lobe epilepsy surgery modulates the activity of auditory pathway. Epilepsy Res. 2014, 108, 748-754. [CrossRef] [PubMed]

10. Morales-Chacon, L.M.; Alfredo Sanchez, C.C.; Minou Baez, M.M.; Rodriguez, R.R.; Lorigados, P.L.; Estupinan, D.B. Multimodal imaging in nonlesional medically intractable focal epilepsy. Front. Biosci. 2015, 7, 42-57. [CrossRef] 
11. Morales, L.M.; Sánchez, C.; E Bender, J.; Bosch, J.; E García, M.; García, I.; Lorigados, L.; Estupiñán, B.; Trápaga, O.; Báez, M.; et al. A neurofunctional evaluation strategy for presurgical selection of temporal lobe epilepsy patients. MEDICC Rev. 2009, 11, 29-35. [PubMed]

12. Chang, E.F.; Raygor, K.P.; Berger, M.S. Contemporary model of language organization: An overview for neurosurgeons. J. Neurosurg. 2015, 122, 250-261. [CrossRef] [PubMed]

13. Blümcke, I.; Aronica, E.; Miyata, H.; Sarnat, H.B.; Thom, M.; Roessler, K.; Rydenhag, B.; Jehi, L.; Krsek, P.; Wiebe, S.; et al. International recommendation for a comprehensive neuropathologic workup of epilepsy surgery brain tissue: A consensus Task Force report from the ILAE Commission on Diagnostic Methods. Epilepsia 2016, 57, 348-358. [CrossRef]

14. Louis, D.N.; Perry, A.; Reifenberger, G.; Von Deimling, A.; Figarella-Branger, D.; Cavenee, W.K.; Ohgaki, H.; Wiestler, O.D.; Kleihues, P.; Ellison, D.W. The 2016 World Health Organization Classification of Tumors of the Central Nervous System: A summary. Acta Neuropathol. 2016, 131, 803-820. [CrossRef] [PubMed]

15. Engel, J. Update on surgical treatment of the epilepsies: Summary of The Second International Palm Desert Conference on the Surgical Treatment of the Epilepsies (1992). Neurology 1993, 43, 1612. [CrossRef]

16. Schramm, J.; Kral, T.; Kurthen, M.; Blümcke, I. Surgery to Treat Focal Frontal Lobe Epilepsy in Adults. Neurosurgery 2002, 51, 644-655. [CrossRef]

17. Binder, D.K.; Von Lehe, M.; Kral, T.; Bien, C.G.; Urbach, H.; Schramm, J.; Clusmann, H. Surgical treatment of occipital lobe epilepsy. J. Neurosurg. 2008, 109, 57-69. [CrossRef]

18. Babajani-Feremi, A.; Rezaie, R.; Narayana, S.; Choudhri, A.F.; Fulton, S.P.; Boop, F.A.; Wheless, J.W.; Papanicolaou, A.C. Variation in the topography of the speech production cortex verified by cortical stimulation and high gamma activity. NeuroReport 2014, 25, 1411-1417. [CrossRef]

19. Téllez-Zenteno, J.F.; Ronquillo, L.H.; Moien-Afshari, F.; Wiebe, S. Surgical outcomes in lesional and non-lesional epilepsy: A systematic review and meta-analysis. Epilepsy Res. 2010, 89, 310-318. [CrossRef]

20. Chaudhry, N.; Radhakrishnan, A.; Abraham, M.; Kesavadas, C.; Radhakrishnan, V.V.; Sarma, P.S.; Radhakrishnan, K. Selection of ideal candidates for extratemporal resective epilepsy surgery in a country with limited resources. Epileptic Disord 2010, 12, 38-47. [CrossRef]

21. Hanáková, P.; Brázdil, M.; Novák, Z.; Hemza, J.; Chrastina, J.; Ošlejšková, H.; Hermanová, M.; Pažourková, M.; Rektor, I.; Kuba, R. Long-term outcome and predictors of resective surgery prognosis in patients with refractory extratemporal epilepsy. Seizure 2014, 23, 266-273. [CrossRef] [PubMed]

22. Englot, D.J.; Breshears, J.D.; Sun, P.P.; Chang, E.F.; Auguste, K.I. Seizure outcomes after resective surgery for extra-temporal lobe epilepsy in pediatric patients. J. Neurosurg. Pediatr. 2013, 12, 126-133. [CrossRef] [PubMed]

23. D'Argenzio, L.; Colonnelli, M.C.; Harrison, S.; Jacques, T.S.; Harkness, W.; Scott, R.C.; Cross, J.H. Seizure outcome after extratemporal epilepsy surgery in childhood. Dev. Med. Child Neurol. 2012, 54, 995-1000. [CrossRef] [PubMed]

24. Elsharkawy, A.E.; Pannek, H.; Schulz, R.; Hoppe, M.; Pahs, G.; Gyimesi, C.; Nayel, M.; Issa, A.; Ebner, A. Outcome of extratemporal epilepsy surgery experience of a single center. Neurosurgery 2008, 63, 516-526. [CrossRef]

25. Vermeulen, L.; Van Loon, J.; Theys, T.; Goffin, J.; Porke, K.; Van Laere, K.; Goffin, K.; Vandenbulcke, M.; Thijs, V.; Van Paesschen, W. Outcome after epilepsy surgery at the University Hospitals Leuven 1998-2012. Acta Neurol. Belg. 2016, 116, 271-278. [CrossRef]

26. Bauer, S.; Hamer, H.M. Extratemporal epilepsies. Handb. Clin. Neurol. 2012, 107, 241-256. [CrossRef]

27. Blümcke, I.; Russo, G.L.; Najm, I.; Palmini, A. Pathology-based approach to epilepsy surgery. Acta Neuropathol. 2014, 128, 1-3. [CrossRef] [PubMed]

28. Kloss, S.; Pieper, T.; Pannek, H.; Holthausen, H.; Tuxhorn, I. Epilepsy Surgery in Children with Focal Cortical Dysplasia (FCD): Results of Long-Term Seizure Outcome. Neuropediatrics 2002, 33, 21-26. [CrossRef]

29. Yao, K.; Mei, X.; Liu, X.; Duan, Z.; Liu, C.; Bian, Y.; Ma, Z.; Qi, X. Clinical characteristics, pathological features and surgical outcomes of focal cortical dysplasia (FCD) type II: Correlation with pathological subtypes. Neurol. Sci. 2014, 35, 1519-1526. [CrossRef] [PubMed]

30. Xue, H.; Cai, L.; Dong, S.; Li, Y. Clinical characteristics and post-surgical outcomes of focal cortical dysplasia subtypes. J. Clin. Neurosci. 2016, 23, 68-72. [CrossRef]

31. Fauser, S.; Bast, T.; Altenmuller, D.M.; Schulte-Monting, J.; Strobl, K.; Steinhoff, B.J. Factors influencing surgical outcome in patients with focal cortical dysplasia. J. Neurol. Neurosurg. Psychiatry 2008, 79, 103-105. [CrossRef] [PubMed]

32. Fauser, S.; Essang, C.; Altenmüller, D.-M.; Staack, A.M.; Steinhoff, B.J.; Strobl, K.; Bast, T.; Schubert-Bast, S.; Stephani, U.; Wiegand, G.; et al. Long-term seizure outcome in 211 patients with focal cortical dysplasia. Epilepsia 2015, 56, 66-76. [CrossRef]

33. Tassi, L.; Pasquier, B.; Minotti, L.; Garbelli, R.; Kahane, P.; Benabid, A.L.; Battaglia, G.; Munari, C.; Spreafico, R. Cortical Dysplasia: Electroclinical, Imaging, and Neuropathologic Study of 13 Patients. Epilepsia 2002, 42, 1112-1123. [CrossRef]

34. Aligholi, H.; Rezayat, S.M.; Azari, H.; Mehr, S.E.; Akbari, M.; Mousavi, S.M.M.; Attari, F.; Alipour, F.; Hassanzadeh, G.; Gorji, A. Preparing neural stem/progenitor cells in PuraMatrix hydrogel for transplantation after brain injury in rats: A comparative methodological study. Brain Res. 2016, 1642, 197-208. [CrossRef]

35. Tassi, L.; Colombo, N.; Garbelli, R.; Francione, S.; Russo, G.L.; Mai, R.; Cardinale, F.; Cossu, M.; Ferrario, A.; Galli, C.; et al. Focal cortical dysplasia: Neuropathological subtypes, EEG, neuroimaging and surgical outcome. Brain 2002, 125, 1719-1732. [CrossRef] [PubMed] 
36. McGonigal, A.; Bartolomei, F.; Régis, J.; Guye, M.; Gavaret, M.; Fonseca, A.T.-D.; Dufour, H.; Figarella-Branger, D.; Girard, N.; Péragut, J.-C.; et al. Stereoelectroencephalography in presurgical assessment of MRI-negative epilepsy. Brain 2007, 130, 3169-3183. [CrossRef] [PubMed]

37. Nobili, L.; Francione, S.; Mai, R.; Cardinale, F.; Castana, L.; Tassi, L.; Sartori, I.; Didato, G.; Citterio, A.; Colombo, N.; et al. Surgical treatment of drug-resistant nocturnal frontal lobe epilepsy. Brain 2006, 130, 561-573. [CrossRef] [PubMed]

38. Bonini, F.; Barletta, G.; Plebani, M. A real-world evidence-based approach to laboratory reorganization using e-Valuate benchmarking data. Clin. Chem. Lab. Med. 2017, 55. [CrossRef]

39. Ravat, S.; Iyer, V.; Panchal, K.; Muzumdar, D.; Kulkarni, A. Surgical outcomes in patients with intraoperative Electrocorticography (EcoG) guided epilepsy surgery-experiences of a tertiary care centre in India. Int. J. Surg. 2016, 36, 420-428. [CrossRef]

40. Hader, W.J.; Tellez-Zenteno, J.; Metcalfe, A.; Hernandez-Ronquillo, L.; Wiebe, S.; Kwon, C.-S.; Jette, N. Complications of epilepsy surgery-A systematic review of focal surgical resections and invasive EEG monitoring. Epilepsia 2013, 54, 840-847. [CrossRef]

41. Behrens, E.; Schramm, J.; Zentner, J.; König, R. Surgical and Neurological Complications in a Series of 708 Epilepsy Surgery Procedures. Neurosurgery 1997, 41, 1-10. [CrossRef] [PubMed]

42. Blount, J.P. Extratemporal resections in pediatric epilepsy surgery-an overview. Epilepsia 2017, 58, 19-27. [CrossRef]

43. Cascino, G.D. Surgical Treatment for Extratemporal Epilepsy. Curr. Treat. Options Neurol. 2004, 6, 257-262. [CrossRef] [PubMed]

44. Sarkis, R.A.; Jehi, L.; Bingaman, W.; Najm, I.M. Seizure worsening and its predictors after epilepsy surgery. Epilepsia 2012, 53, 1731-1738. [CrossRef] [PubMed] 